\title{
NAMING DENTAL AND ORAL ANOMALIES
}

\author{
George R. Moore,* D.D.S., M.S., Ann Arbor, Mtch.
}

D

ENTAL terminology is, this year, in its perennial state of disorder. Fully aware of this fact, our practical-minded chairman, in planning this meeting, decided to include the solemn subject of nomenclature, on condition that it could be treated in a practical manner consistent with the remainder of this program. He was able to extract from me, in an unguarded moment, a promise to write a paper on the subject; and with the thought that I would receive unlimited assistance from the other members of the nomenclature committee, I proceeded with the assignment. I had not gone far before I discovered that nomenclature committee members are somewhat soured on the world. Nomenclature committees usually include men who have served a sufficient number of years to become justly impressed with the futility of trying to do something about the terminology of their specialty. Fortunately, I learned this early enough so that I could at least begin to understand why it is true.

As I said, the attitude which they assume is justifiable. Now why is it so? In the first place, our committees on nomenclature have always tried to worry along singlehandedly, for the most part. True, some of the broader minds of years past have made an honest endeavor to render our terminology consistent with that of general dentistry, hopeful of avoiding irreconcilable differences between considered definitions of the same term when supplied by authorities from different fields of dentistry; but most efforts of this kind have failed.

It has becn repeatedly suggested that our terminology be made consistent with that of medicine and other sciences. At the same time we are confronted with statements such as this one found in a report of the Committee on Nomenclature of the American Dental Association in 1925: "The committee is aware that some of its recommendations seem arbitrary and in conflict with medical nomenclature but we also are aware of the fact that our object and purpose are primarily to make dental terms understandable to dentists."

As long as this view continues to oceupy the minds of nomenclature committee members of the various specialties of dentistry, we shall continue to stifle growth and development of the profession along medical and scientific lines. Such an attitude is responsible for the recommendation that the words "bicuspid" and "cuspid" be used when speaking to dentists in order that they may understand; although "premolar" and "canine" must be used in papers prepared for other scientific bodies.

True, these terms might be defended on the basis of custom and long use. Usage is generally the best determinant of values, especially among educated people, unless there be some well-founded or scientific reason for a change. I ast

*Professor of Orthodontics, University of Michigan, School of Dentistry.

Read before the Thirty-Sixth Annual Meeting of the American Association of Orthoclontists, Los Angeles, Calif., July, 1938. 
year, our committee found this to be the case in respect to the term "orthodontia." Usage alone, in this country, might have indicated the continuation of that term, in spite of the fact that it never has been widely used in Europe. It was learned, however, that American usage was the sole defense that could be claimed in support of its survival and that regardless of how well educated an individual might be in general or scientific matters, he had to be directly familiar with the field of orthodontics-or else somewhat of a clairvoyant-to understand the term "orthodontia." It did not suggest its meaning.

Professor Hereward Price, of the Oxford Dictionary Staff and member of the faculty of the University of Michigan, has aptly expressed the situation as follows: "The term 'orthodontia' suggests that it means a flower, a disease, or a city in Asia. 'Orthodonties,' on the other hand, is neat in appearance, easy to pronounce, and tells you at once, more or less, what it means. It is on a line with 'physics' and 'statics' and similar words. The case of 'ics' is still more simple. Since the fifteenth century it has been used in English to denote a science. It is a direct translation from the Greck, and we may say that this sort of ending has been used to denote a science for thousands of years. If you speak of 'orthodonties,' I know at once that you are speaking about a science and do not need to start guessing wildly in which of half-a-dozen eategories I must place this word."

One needs only to begin the critical examination of our nomenclature before one wonders how such errors came into existence and gained such wide usage. Perhaps it has been the result of too much freedom in the coinage of terms, without analyzing thoroughly the meaning of the roots of the word involved. When word coinage is contemplated, it would be a very easy matter to consult an etymologist or philologist and check the term before even introducing it. If this had bcen done with "orthodontia," the word would never have come into cxistence. It is the same with nomenclature as with any other field of knowledge: there are specialists for the coining of words just as there are specialists concerned with correcting facial deformity; and when we presume to coin words without expert advice, we are overstepping our bounds just as surely as the etymologist would be overstepping his if, without license, he presumed to treat the dental ills of his neighbor's child.

In a nomenclature report by Dr. W. L. Fickes in the 1926 Proceedings of the American Association of Dental Schools, he suggested that a questionnaire be sent with each list of words being examined by dental teachers with reference to their eligibility to remain a part of the accepted language of the profession. Among the questions to be answered were these: Is the word in current use? How often used? Is it a new word? Is it etymologically correct? Should it be recorded in the list of acceptable terms? Should it be placed on probation in a working list? Should its use be discouraged? Should it be deleted? Is it scientifically correct in its relation to dental subjects? Is it misleading in its relation to facts or correct teaching?

I believe another question might well be added; namely, is it correct in its relation to medicine and general science? Usage is important, but the order of the questions in this list indicates that the author regards it as more important than it actually should be. 
It seems to me that a similar, though shorter, list of questions might be prepared as a guide for members of the profession who feel the urge to coin new terms. For example: Is the new term etymologically correct? Does it replace a term which is etymologically incorrect? Is it a simpler form? Does it sound pedantic in comparison with the old term which is not glaringly incorrect or inadequate? Is the suggested word a half-caste word of mixed Greek and Latin parentage?

I would agree with the writer of an editorial in the June, 1925, Dental Cosmos, who says, "Much may be said in favor of systematic technical terminology in dentistry as in every activity having pretensions to a scientific basis; we will even applaud prophylaxis, apicoectomy, periodontoclasia, and the others, if, by reason of these verbal ponderosities, the results relating to the things they designate will thrive and improve pari passu with their impressiveness as related to the professional dignity of the respective specialists on the one hand and their fee-compelling influence on the other. It has been argued that this type of terminology is consistent with medical ideals and its use therefore enhances the professional flavor and atmosphere of dentistry; possibly so, yet can it be denied that there is about it a suggestion of pedantry, a straining after effect, therefore a suspicion of disingenuousness that is not wholly compatible with the spirit of scientific truth? Is it not just this lack of directness and simplicity about much of our professional terminology or its implication of mysticism and insincerity that raises a smile in the thoughtful when some of our professional terms are given a public airing?"

Very few new terms have been suggested by orthodontists within the past year, so I presume that I shall be forgiven by our president if I publicize two which he suggested. I am not trying to polish the apple but I do wish to refer to the terms "eugnathia" and "dysgnathia" as exhibiting all the earmarks of the most meticulous care in their selection. The prefix "eu" is understood by our Greek scholars to mean "well," implying "normal"; and the prefix "dys" as meaning "bad," implying "abnormal." In Dr. McCoy's paper, "The Diagnosis and Treatment of Deficient Mandibular Structures in Children," published in the June, 1937, issue of the Journal of the American Dental Association, he makes the following statement: "All anomalies will fall under two general classifications; namely, those designated as eugnathic, in which the teeth only are involved and those termed dysgnathic, in which the maxilla or the mandible or both are included in the deformity. This latter group is the more serious and requires the greatest judgment and skill in both diagnosis and treatment. In this group (dysgnathic anomalies) are to be found those cases where, inclusive with other anomalies, the mandibular structures are underdeveloped and frequently malrelated in their facial relationships." We are indebted to Dr. MeCoy not only for the addition of these terms to our nomenclature but for his impeccable adherence to accepted standards governing word coinage.*

\footnotetext{
*In the discussion following the reading of this paper the statement was made that Dr. B. E. Lischer had previously used these terms. The author does not wish to assign credit for the origin of these words but rather wishes to use them as examples of proper principles of word coinage.
} 
Dr. C. C. Howard must have had in mind the need for such a distinction in terms when he suggested, some time ago, the terms "growth case" and "nongrowth case," meaning that some cases were involved in malalignments without apical base involvements and other cases, the reverse. The terms eugnathic and dysgnathic convey their full significance elosely bound up in the meaning of their own roots without need for additional explanation and therefore without hazard of misinterpretation. This feature is a defense for any newly coined term, and I bring it up as an example of how, in the future, one should go about the coining of new words-if coin he must--keeping in mind that there is no particular virtue in the act.

In a helpful letter recently received from Dr. Bernard Wolf Weinberger, who is a fellow member of this committee, he makes the following statement: "I am absolutely opposed to the present trend of coining new words and definitions unless it will fit in with co-related sciences." So much for word coinage.

Now let us read what Dr. Weinberger has to say further concerning correlated nomenclature: "The time is long past when dentistry can consider itself something separate. Whether we are part of the medical profession or not is a thing that can be answered in several ways, but if dentistry wants to be accepted as a science, it must realize that it is but a part of a large group and therefore must fit in with others: that dentistry is not something which belongs to the United States, but is a part of the F. D. I., an international institution, and that before we accept our own conclusions these must be submitted to the above organization for their consideration and something adopted that can be used universally. Orthodontia is a part of dentistry in that respect, and dentistry is a part of medicine, anthropology, etc.

"Some years ago, I suggested . . . that the whole matter be approached from a different angle . . but nothing came of it. It is for that reason $I$ feel that whatever effort is made by the American Association would be of little value. There is altogether too much confusion because more do not undcrstand our own aims. There is no better example than the controversy now existing regarding abbreviations of dental periodicals. There is a tremendous amount of work which should be done; but, unless it can be done along the lines above suggested, I personally believe it would be time wasted. For years the society has asked men to appear before it, such as Gregory and Hrdlicka, and yet is not willing to work with these men in adopting for dentistry a nomenclature which has been accepted by them for hundreds of years and is internationally understood. I trust that I have made the point clear."

Now, from Dr. Weinberger's remarks and those of my own which preceded them, you can well see what the situation is and what hope we have of improving it as long as we remain apart from organized activities of nomenclature committees in all other allied fields. If we will but look beyond our noses, we shall find two very well established systems of nomenclature to link up with, contribute to, and receive benefit from. One of these is the National Conference on Nomenclature of Disease, whose origin may be traced briefly as follows: The first system of nomenclature of diseases was devised 101 years ago by William Farr in London. For 90 years medicine evidently had troubles similar to those our profession is having. The medical nomenclatures in use throughout the United 
States varied in form from alphabetical lists of diseases to elaborate classifications. Hospitals, health organizations, and insurance companies were obliged to devise their own nomenclatures or, having borrowed an existing one, promptly proceeded to modify it beyond recognition. This confused multiplieity of effort was due to the absence of any central guiding influence. In each new nomenclature, the terminology employed represented the personal choice of the author and was therefore open to individual criticism and continuous alteration.

For the purpose of remedying the existing confusion, a conference on nomenclature of diseases was held in New York on March 22, 1928. Invitations to this conference included the American College of Surgeons, the American Heart Association, the American Hospital Association, the American Statistiral Association, the American Suroiral Association, the Association of American Physicians, several of the larger New York hospitals, and the following federal services: Bureau of the Census, United States Public Health Service, the Medical Department of the Army, and the Medical Department of the Navy. At this meeting, the present organization, The National Conference on Nomenclature of Disease, was formed, the primary object of which was to unite the important national societies representing medicine, surgery, and their specialties, the federal medical services and interested national health organizations and life insurance interests in an effort to develop a standard national nomenelature of diseases.

The first publication of this organization, called, "The Standard Classified Nomenclature of Disease," appeared in April, 1932, and revisions and reprintings have occurred regularly since that time with the financial support of the Commonwealth Fund. A group of 14 large and small hospitals installed the new nomenclature in their record rooms in order to subject it to an intensive trial. In 1932, 22 national clinical and other societies voted their approval of the work at their annual meetings.

This nomenclature has been designed primarily for clinicians. Therefore, the clinical point of view has always been permitted to dictate a possible choice of terms or arrangements, provided it was not at variance with scientific accuracy or completeness. This concerted cffort on the part of various fields of medicine cannot fail to exereise an influence upon the accuracy and preeision of medical thought.

What objection could there be to the inclusion of dentistry and its various specialties among the group collaborating on this piece of work? The only difficulty I see would be one existing within ourselves: an unwillingness on the part of our membership to follow the lead of nomenclature committees who wish to lay aside all petty or political prejudices concerning present terminology. Medicine has not had to throw away all its old terms and neither would we; but cooperation with committees in other fields whose present activities have evolved from decades of slow advance would benefit us much.

The title of this paper confines it to the names of anomalies. There is the anatomical, as distinguished from the pathological side of our nomenclature, however, which must also be recognized. This brings us 10 a consideration of the 
advisability of cooperating with those who occasionally re-edit what is called the "Basel Nomina Anatomica," known as the B. N. A. This compilation of terms was first published in 1901, after six years of work during which the committee reduced 30,000 anatomical terms to a mere 5,000 by omitting the mass of synonyms. The B. N. A. is kept in practically a constant state of revision; and, although there might be difficulties involved in the inclusion of our anatomical terms, we could a.t least make an attempt; and I suspect that practically every anatomical term which has a right to continue in use would be found already in the B. N. A. Our recommendation is that the Nomenclature Committee of the American Association of Orthodontists be instructed to investigate the possibility of an affiliation with those in charge of the National Conference on the Nomenclature of Disease, and also with the B. N. A., and report progress at the next meeting.

Not all dental terms will be included in the two above categories, since there are chemical, physical, metallurgical, and engineering terms, ete., also to be considered. These, likewise, should be maintained in a state consistent with allied scientific nomenclatures.

Some of you will inquire why no comment has been made concerning such glaring misnomers as distoclusion, posteroclusion, mesioclusion, anteroclusion, and a host of such terms. Others will inquire why their pet terms, anteversion, retroversion, protraction, retraction, etc., have not been endorsed in this report. In reply to these and all other queries, it may be said that such action must be taken only after painstaking and closely coordinated action on the part of the committee, guided by the principle of elose interrelationship with medical and other allied scientific nomenclatures. When such a plan is finally endorsed, it will then be the duty of our committee to renovate completely the professional language; cull out all etymologically indefensible terms; publicize its activities in a separately edited portion of the American Journal of Orthodontics; argue with the profession directly and through the JoURNAL for a few years; and as rapidly as possible publish a list of approved terms and a list of obsolete terms recently condemned. Success of the above suggestions, however, is contingent on one thing; namely, whether or not we first affiliate with the National Conference on the Nomenclature of Disease, and with the B. N. A.

Again, in closing, we recommend that the Association instruct its Nomenclature Committee to investigate ways and means of bringing this about. 